\title{
Editorials
}

\section{Financial conflict of interest among clinical practice guideline-producing organisations}

\section{INTRODUCTION}

Competing interests between biomedical industry objectives and the public good raise concerns that some clinical practice guidelines sponsored by industry may not serve patients or the public as they should. ${ }^{1,2}$

GPs and other guideline users are likely unaware of the extent of organisational financial conflict of interest (FCOI) due to industry sponsorship of guidelineproducing organisations. Understanding how guidelines are susceptible to bias when such organisational FCOI is present and potential mitigating strategies helps critically appraise guidelines that are encountered in practice.

\section{EXTENT OF ORGANISATIONAL FCOI}

loannidis has warned guideline users that some guideline-producing societies are 'behemoth financial enterprises.3 The American Heart Association receives almost 200 million USD annually from corporate sponsors, and the European Society of Cardiologists receives over 45 million Euros annually, $77 \%$ of their 60 million Euro budget. ${ }^{3}$ Despite this, little attention has been paid to the extent to which guideline producers are dependent on industry funds and how infrequently this is disclosed. A 2016 study found that financial relationships between guideline producers and biomedical companies were disclosed in only $1 \%$ of 290 guidelines, even though (when verification was possible) the majority of producers received funds from a biomedical company. ${ }^{4}$ More recently, almost all Canadian professional societies and disease condition organisations that published clinical practice guidelines from 2016-2018 were found to receive industry funding (93\%), but none identified this within a guideline, nor described policy to manage organisational FCOI in a guideline that they sponsored. ${ }^{5}$ In all cases, the industry funder produced a drug that was evaluated in the guideline. More comprehensive $\mathrm{FCOI}$ policies are associated

\section{"Longstanding and substantial organisational FCOI [financial conflict of interest] among guideline producers has remained largely hidden and unchecked.}

with less enthusiastic recommendations for medical products, ${ }^{4}$ which emphasises the importance of FCOls as a critical barrier to guideline trustworthiness.

\section{ORGANISATIONAL FCOI AND RISK OF BIAS IN RECOMMENDATIONS}

Clinical practice guidelines are vulnerable to multiple sources of bias. Organisations that oversee guideline development and guideline panels make decisions that can influence the ultimate recommendations, including who to invite as panel members, who will author and lead (chair) the guideline, which topics to consider, and what questions to address. They also make value-based judgements about which evidence to include, the certainty of that evidence, and the net effect of benefits relative to harms. Bias in clinical practice guidelines has also been associated with panel member $\mathrm{COI}^{6}{ }^{6}$ the failure to involve objective methodologists in evidence synthesis and interpretation, ${ }^{7}$ and the lack of meaningful input from relevant patient and clinician stakeholders who will use or be affected by recommendations. ${ }^{6,7}$ In this context, organisational FCOI may play an important role in shaping recommendations and may compound such other sources of potential bias.

Two oversight organisations, the US Institute of Medicine lnow the National Academy of ${\text { Medicine })^{8} \text { and Guidelines }}^{2}$ International Network (GIN), ${ }^{9}$ provide guidance on disclosure and management of individual-level COI but neither agency is explicit about organisational-level FCOI.

\footnotetext{
"Urgent and effective reform is needed, ideally driven by membership pressure from professional societies, disease condition organisations, oversight agencies, and journal editors.
}

This gap in oversight requires guidelineproducing organisations to disclose and manage their FCOls. This has largely failed ${ }^{4,5,10}$ and more robust solutions are required.

\section{MITIGATING AGAINST ORGANISATIONAL FCOI}

At a minimum, similar to FCOI among guideline panel members, disclosure, publication, and management of organisational FCOI must occur for guideline trustworthiness. The National Academy of Medicine and GIN should refine their stated principles to ensure that organisations disclose the overall amount of relevant industry funds directed to the guidelineproducing organisation, and specifically the proportion of guideline budget from these sources. Additional information about the sponsor's role that should be reported within guidelines includes: involvement in committee member selection; framing the guideline agenda (for example, topic selection and key question formulation); involvement in evidence review and synthesis processes; manuscript writing; reviewing recommendations prior to publication; and disclosure of any on-patent drug or device interests. The GIN-McMaster guideline planning checklist, ${ }^{11}$ recommends that guideline producers advocate for public funding with the goal of no commercial sponsorship, accept commercial sponsorship only from entities that are unrelated to the guideline topic, only seek commercial support for indirect guideline activities (for example, translation), and avoid single-source sponsors. Commissioning an arm's length group (for example, a government agency or university ethics review board) to oversee interactions and compliance with organisational FCOI policy has also been proposed to disentangle interests. ${ }^{2}$ Currently, users of clinical practice guidelines are largely left on their own to discern whether guideline producers may 


\section{"GPs, individually and organisationally, can also play a role and serve their patients better by insisting that the clinical practice guidelines that they use meet minimum standards for trustworthiness.}

have industry-related $\mathrm{FCOI}$ and whether it could have influenced recommendations.

Journals that publish clinical practice guidelines must move beyond token gestures of $\mathrm{COI}$ disclosure, particularly when establishing criteria for disclosure of organisational FCOI, making it evident how organisational FCOI may influence study conclusions and guideline recommendations. Indeed, given the extent of unreported individual and organisational FCOls, journals should require audited financial statements from organisations that sponsor clinical practice guidelines.

In the meantime, GPs could prioritise guidelines from organisations that do not receive biomedical industry funding and are recognised for their rigour, such as the Canadian Task Force on Preventive Health Care, the United States Preventive Services Task Force, and the National Institute for Health and Care Excellence.

\section{CONCLUSION}

Longstanding and substantial organisational FCOI among guideline producers has remained largely hidden and unchecked. Urgent and effective reform is needed, ideally driven by membership pressure from professional societies, disease condition organisations, oversight agencies, and journal editors. GPs, individually and organisationally, can also play a role and serve their patients better by insisting that the clinical practice guidelines that they use meet minimum standards for

\section{Ainsley Moore,}

Associate Professor, Family Medicine, McMaster University, Hamilton, Ontario.

\section{Sharon Straus,}

Director, Knowledge Translation Program, Li Ka Shing Knowledge Institute, St Michael's Hospital, Toronto, Ontario.

\section{Joel Lexchin,}

Professor Emeritus, School of Health Policy and Management, York University, Toronto, Ontario.

\section{Brett D Thombs,}

Professor and Senior Investigator, Faculty of Medicine, Lady Davis Institute at the Jewish General Hospital, McGill University, Montréal, Québec

\section{Provenance}

Commissioned; externally peer reviewed

\section{Competing interests}

The authors have declared no competing interests.

DOI: https://doi.org/10.3399/bjgp20X713177 trustworthiness.

\section{ADDRESS FOR CORRESPONDENCE}

\section{Ainsley Moore}

Stonechurch Family Health Centre, 1475 Upper Ottawa Street, Hamilton, Ontario L8W 3J6, Canada.

\section{Email: amooreamcmaster.ca}

\section{REFERENCES}

1. Jørgensen AW, Hilden J, Gøtzsche PC. Cochrane reviews compared with industry supported meta-analyses and other metaanalyses of the same drugs: systematic review. BMJ 2006; 333(7572): 782.

2. Sniderman $A D$, Furberg $C D$. Why guidelinemaking requires reform. JAMA 2009; 301(4) 429-431.

3. Ioannidis JPA. Professional societies should abstain from authorship of guidelines and disease definition statements. Circ Cardiovasc Qual Outcomes 2018; 11(10): e004889.

4. Campsall P, Colizza K, Straus S, Stelfox HT Financial relationships between organizations that produce clinical practice guidelines and the biomedical industry: a cross-sectional study. PLoS Med 2016; 13(5): e1002029.

5. Elder $\mathrm{K}$, Turner KA, Cosgrove $\mathrm{L}$, et al. Reporting of financial conflicts of interest by Canadian clinical practice guideline producers: a descriptive study. CMAJ 2020; 192(23): E617-E625.

6. Agoritsas T, Neumann I, Mendozza C Guyatt GH. Guideline conflict of interest management and methodology heavily impacts on the strength of recommendations: comparison between two iterations of the American College of Chest Physicians Antithrombotic Guidelines. J Clin Epidemiol 2017; 81: 141-143.

7. Cosgrove L, Shaugnessey AF Peters SM, et al. Conflicts of interest and the presence of methodologists on guideline development panels: a cross-sectional study of clinical practice guidelines for major depressive disorder. Psychother Psychosom 2017; 86(3): 168-170.

8. Schünemann HJ, Al-Ansary LA, Forland F, et al. Board of Trustees of the Guidelines International Network. Guidelines International Network: principles for disclosure of interests and management of conflicts in guidelines. Ann Intern Med 2015; 163(7): 548-553.

9. Institute of Medicine (US) Committee on Standards for Developing Trustworthy Clinical Practice Guidelines. Clinical practice guidelines we can trust. Washington, DC: National Academies Press, 2011.

10. Mitchell AP, Basch EM, Disetzina SB. Financial relationships with industry among National Comprehensive Cancer Network guideline authors. JAMA Oncol 2016; 2(12): 1628-1631.

11. Schünemann HJ, Wiercioch W, Exteandia I, et al. Guidelines 2.0: systematic development of a comprehensive checklist for a successful guideline enterprise. CMAJ 2014; 186(3): E123-E142. 